\title{
Experimental investigation of explosive vaporization of liquids on the flat microheater
}

\author{
Igor Kozulin ${ }^{1,2}$ * \\ ${ }^{1}$ SB RAS, Institute of Thermophysics, Prospect Akademika Lavrentjeva 1, \\ Novosibirsk 630090, Russia \\ ${ }^{2}$ Novosibirsk State University, Pirogova str.,1, Novosibirsk 630090, Russia
}

\begin{abstract}
The initial stage of controlled decay of metastable liquid was studied under pulsed heating on the surface of the flat microheater using the optical method of reflected laser beam. Four major stages of fluids explosive boiling and phase explosion on microheater were determined. The dynamics of filling the heater surface with the vapor phase, the lifetime of the main vapor bubble, and the satellite bubble are estimated.
\end{abstract}

\section{Introduction}

Researches of heat and mass transfer with phase change in microfluidic systems are rapidly developed. This is related to a growing interest in the MEMS technology (microelectromechanical systems). The MEMS technology makes it possible to obtain extremely high temperatures without the breakdown of the microheater. This is also concerned with studying the vapor phase nucleation, spinodal liquid decomposition, bubble dynamics, etc. Experimental investigations of the explosive boiling on the flat microheater were performed in [1-4]. In this case, the decay of liquid metastable state occurs near the temperature of limit overheating. The regularities of water micro volumes at explosive boiling were numerically established in [5] at the high-impact thermal pulses using multilayer microheater coated submicron silicon carbide layer. The aim of this work is an experimental study of the initial stage of explosive boiling of liquids (water, propanol-1) on a microheater using an original optic system.

\section{Experimental setup}

The experimental setup for studying the dynamics of explosive boiling on the microheater is shown in Fig. 1, (a). The microheater is a multilayer thin-film resistor of the Hewlett Packard ThinkJet printhead [6]. The microheater's photo is presented in Fig. 1, (b). The size of microheater is $100 \times 110 \mu \mathrm{m}$. The microheater is a four-layer film deposited layer-bylayer by the PECVD method in a thin glass substrate. The first layer is a silica $1.1 \mu \mathrm{m}$, thick followed by a $0.5 \mu \mathrm{m}$ heat-emitting $\mathrm{TaAl}$ layer, whose conduction is weakly dependent on

* Corresponding author: kozulin@itp.nsc.ru 
the temperature, and a $0.25 \mu \mathrm{m} \mathrm{SiC} \mathrm{layer.} \mathrm{This} \mathrm{sandwich-like} \mathrm{structure} \mathrm{of} \mathrm{the} \mathrm{heater}$ ensures high growth rates of the water layer temperature under pulse heating.

The microheater (1) is immersed in the working fluid (2), and its surface is lit by laser (3). The initial temperature of the liquid was determined before the experiment and ranged from 18 to $21^{\circ} \mathrm{C}$, the experiments were conducted at atmospheric pressure. The single rectangular current pulse is supplied to microheater from the 214B Hewlett Packard pulse generator. Each pulse has sufficient duration for the explosive boiling of liquid near the surface of the microheater. The initial stage of explosive boiling was studied using the optical registration, based on measuring the intensity of the laser beam (3) reflected from the mirrored surface of the microheater (1). The reflected laser beam from the heater enters to the microscope (4). The diaphragm (5) selects an area with the microheater surface. The intensity of the laser beam is measured by the photodiode (6). The signal from photodiode is registered with the high-speed ADC (7). The integral coefficient of the reflection of laser light begins to decrease during the appearance of microbubbles on the microheater. The signal from the photodetector provides the information about the history of the heater surface coverage by vapor bubbles.

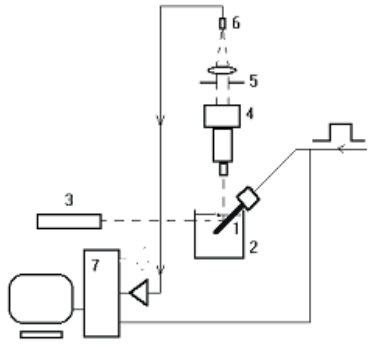

(a)

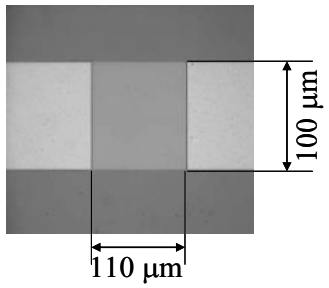

(b)

Fig. 1. Experimental setup (a), photo of the multilayer thin-film microheater (b).

\section{Experimental results}

Figure $2(a, b)$ shows the dynamics of surface coverage by the bubbles during the explosion boiling of water on the microheater. The normalized signal from the generator is also shown in Fig. 2 by a thin line. The dark line shows the dependence of reflected light intensity from the microheater according to the time during the explosion boiling of water. Figure 2 (a) shows the dynamics of surface coverage during the explosion boiling of water for the effective heat flux $\mathrm{q}_{\mathrm{eff}}=579.18 \mathrm{MW} / \mathrm{m}^{2}$, the growth rate of temperature $\mathrm{dT} / \mathrm{dt}=51.89 \mathrm{MK} / \mathrm{s}$ and duration of the heating pulse $\mathrm{t}=4.144 \mu \mathrm{s}$. Figure $2(\mathrm{~b})$ shows the dynamics of surface coverage for the effective heat flux $\mathrm{q}_{\mathrm{eff}}=2906.2 \mathrm{MW} / \mathrm{m}^{2}$, the growth rate of temperature $\mathrm{dT} / \mathrm{dt}=450.42 \mathrm{MK} / \mathrm{s}$ and duration of the heating pulse $\mathrm{t}=0.192 \mu \mathrm{s}$. The zero time in Fig. 2 corresponds to a supply of heat pulse from the generator.

Letters A, B, C, D and E in Fig. 2 (a, b) identify four basic stages of explosive boiling of liquid. The first stage from point $\mathrm{A}$ to point $\mathrm{B}$ corresponds to the heating of the liquid by heating pulse from the generator. The signal increased in this area because of the change of the optical properties of the liquid near the microheater surface. The second stage starts from point $\mathrm{B}$ which corresponds to the first appearance of bubbles on the surface of microheater and continues to point $\mathrm{C}$. It corresponds to the growth of number of the bubbles on the microheater, which causes a sharp decrease of the reflected laser beam intensity scattering on the bubbles. The exponential growth of the bubbles number is determined by the frequency of homogeneous nucleation [2]. 


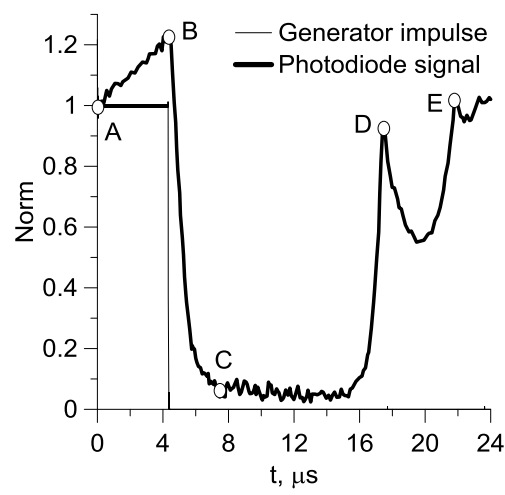

(a)

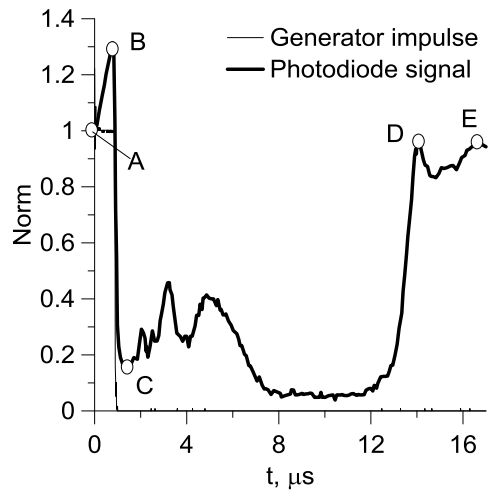

(b)

Fig. 2. The intensity of the reflected laser beam depending on the time during the explosion boiling of water: (a) $\mathrm{q}_{\text {eff }}=579.18 \mathrm{MW} / \mathrm{m}^{2}, \mathrm{dT} / \mathrm{dt}=51.89 \mathrm{MK} / \mathrm{s}, \mathrm{t}=4.144 \mu \mathrm{s}$, (b) $\mathrm{q}_{\mathrm{eff}}=2906.2 \mathrm{MW} / \mathrm{m}^{2}, \mathrm{dT} / \mathrm{dt}=450.42$ $\mathrm{MK} / \mathrm{s}, \mathrm{t}=0.912 \mu \mathrm{s}$.

Figure 3 (a) shows the intensity of the reflected laser beam depending on the time during the explosion boiling of water for an increased effective heat flux. The normalized signal from the generator is presented by the thin line. The dark line shows the dependence of intensity of reflected light according to the time during the explosion boiling of water for the effective density of heat flux $\mathrm{q}_{\mathrm{eff}}=4319.8 \mathrm{MW} / \mathrm{m} 2$, the growth rate of temperature $\mathrm{dT} / \mathrm{dt}=702.49 \mathrm{MK} / \mathrm{s}$ and duration of the heating pulse $\mathrm{t}=0.692 \mu \mathrm{s}$. The signal detailing from the photodiode is shown in Fig. 3 (b). It is seen that for a temperature growth rate higher than $500 \mathrm{MK} / \mathrm{s}$, the nature of the signal changes. There are oscillations in a signal from the photodiode, which may indicate an earlier formation of the vapor cavity due to the unification of the bubbles. A comparison of the reflected light intensity and photographs obtained using a pulsed laser, showed that this behaviour is caused by the appearance of a powerful evaporation wave at the initial stage of explosion and transition to a continuous vapor film that reflects light well.

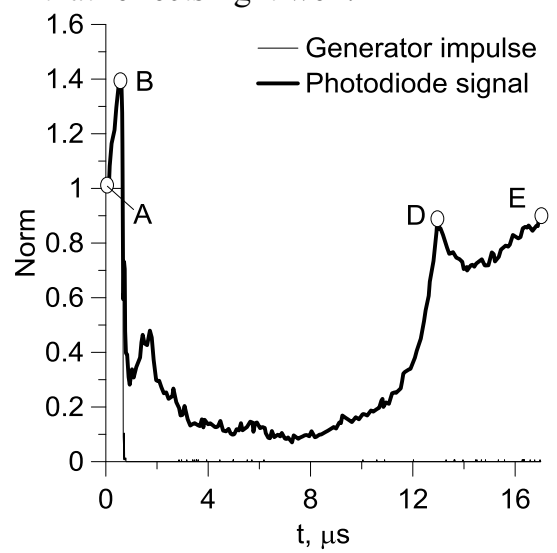

(a)

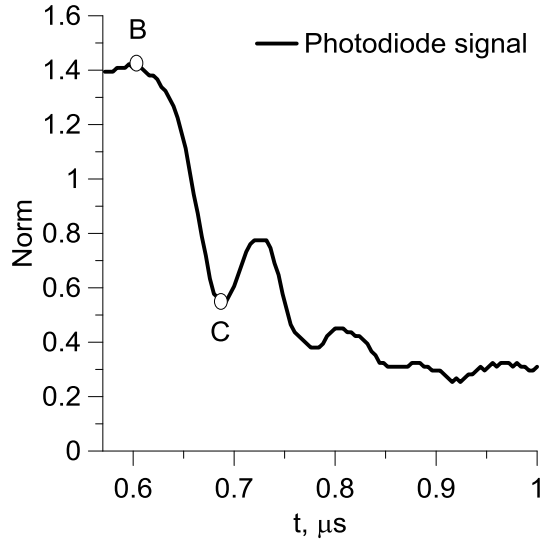

(b)

Fig. 3. (a) The intensity of the reflected laser light depending on the time during the explosion boiling of water $\mathrm{q}_{\mathrm{eff}}=4319.8 \mathrm{MW} / \mathrm{m}^{2}, \mathrm{dT} / \mathrm{dt}=702.49 \mathrm{MK} / \mathrm{s}, \mathrm{t}=0.692 \mu \mathrm{s}$, (b) the signal detailing. 


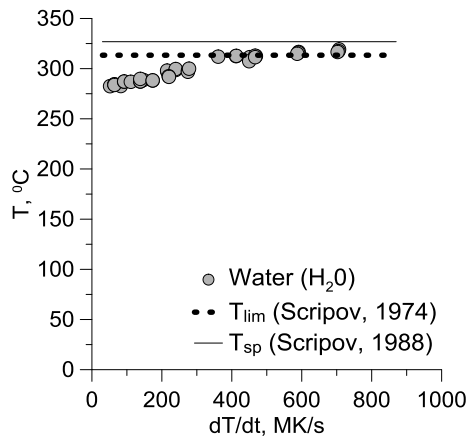

(a)

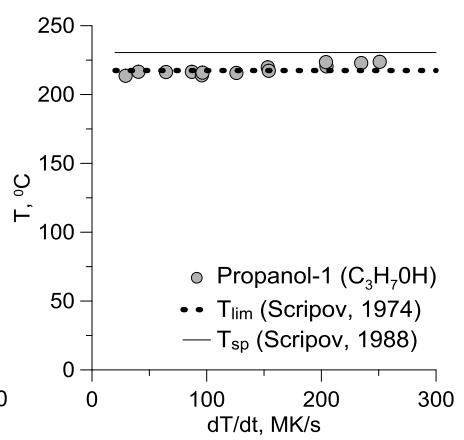

(b)

Fig. 4. The dependence of start temperature of the explosion boiling from the growth rate of temperature: (a) water, (b) propanol-1.

The dependence of temperature of the explosion boiling initiation from the temperature growth rate for water and propanol-1, is presented in Fig. $4(\mathrm{a}, \mathrm{b})$. Here, the dotted line presents the solution of an equation $\mathrm{T}_{\mathrm{lim}} / \mathrm{T}_{\mathrm{cr}}=0.905+0.095 .\left(\mathrm{T}_{\mathrm{sat}} / \mathrm{T}_{\mathrm{cr}}\right)^{8}$ for limiting overheating of liquid based on the data of [7]. The solid line shows the spinodal line calculated according to [8].

\section{Conclusion}

The analysis of dynamics of the explosive boiling of liquids (water, propanol-1) on the microheater with dimensions of $100 \times 110 \mu \mathrm{m}$, is presented in this paper. The investigation has shown that the used method ensures a high accuracy of measuring a part of the heater surface filled with vapor bubbles. It allows measuring the time point corresponding to beginning of explosive vaporization, the duration of the bubble liquid decomposition, and the lifetime of the main vapor bubble and the satellite bubble. The determined temperature growth rate that corresponds to the change in the mode of vapor phase generation shows a change of the mechanism of the liquid decay in the vicinity of spinodal at a high liquid temperature growth rate.

This work was performed at Kutateladze Institute of Thermophysics SB RAS supported by a grant from the Russian Science Foundation (project No. 16-19-10519).

\section{References}

1. Y. Hong, N. Ashgriz, J. Andrews, J. Heat Transfer 126, 259 (2004)

2. V.V. Kuznetsov, I. A. Kozulin, J. Eng. Thermophys. 19, 102 (2010).

3. V.V. Kuznetsov, V.I. Oreshkin, A.S. Zhigalin, I.A. Kozulin, S.A. Chaikovsky, A.G. Rousskikh, J. Eng. Thermophys. 20, 240 (2011)

4. V.V. Kuznetsov, I.A. Kozulin, O.V. Vitovsky, J. of Eng. Thermophys. 21, 136 (2012)

5. V.V. Kuznetsov. J. Physics: Conference Series. 754, (2016)

6. E.V. Bhaskar, J.S. Aden, Hewlett-Packard J. 36, 27 (1985)

7. V.P. Skripov, Metastable liquids (John Wiley \& Sons, 1974)

8. V.P. Skripov, E.N. Sinitsyn, P.A. Pavlov, G.V. Ermakov, G.N. Muratov, N.V, Bulanov, V.G. Baidakov, Thermophysical properties of the liquids in the metastable (superheated) state (Gordon and Breach Science Publishers, New York, 1988) 